\title{
PENGGUNAAN LIDAR (LIGHT DETECTION AND RANGING) UNTUK MENGUKUR KEDALAMAN PERAIRAN DANGKAL
}

\author{
Oleh \\ Hollanda A Kusuma ${ }^{1)}$ dan Nadya Oktaviani ${ }^{2)}$
}

\begin{abstract}
ABCTRACT
UTILIZATION OF LIDAR (LIGHT DETECTION AND RANGING) TO MEASURE SHALLOW WATER DEPTH. Understanding on seabed characteristics such as the topography, composition and habitat conditions was very important to provide information not only for shipping activities, conservation, management and planning activities, but also for research activities with accurate bathymetry data. Accurate bathymetric data can be obtained from hydrographic surveys and remote sensing technology analysis. The hydrographic survey is used to obtain bathymetry data by applying singlebeam echosounder (SBES) and multibeam echosounder (MBES). At a depth of $<15 m$ (shallow water) was difficult to carry out an acoustic survey. At present there is one remote sensing technology that can be used to support hydrographic surveys namely Bathymetric LIDAR (Light Detection and Ranging). LIDAR was able to detect objects on land and waters due to being flown by a vehicle. Wide LIDAR sweep makes data acquisition faster and more effective than acoustic noise. Therefore, LIDAR was an alternative to obtain depth data, especially in coastal areas with a depth of less than $50 \mathrm{~m}$.
\end{abstract}

Keyword: LIDAR, Bathymetry, shallow water

\section{PENDAHULUAN} Pemahaman mengenai
karakteristik dasar laut seperti kondisi habitat sangat penting untuk memberikan informasi bagi kegiatan pelayaran, konservasi, manajemen dan perencanaan, serta kegiatan penelitian yang membutuhkan data batimetri yang akurat. Data batimetri yang akurat dapat diperoleh dari survei hidrografi dan analisa teknologi penginderaan jarak jauh.

\begin{abstract}
Survei hidrografi digunakan untuk memperoleh data batimetri dengan pemeruman secara akustik menggunakan singlebeam echosounder (SBES) dan multibeam echosounder (MBES). Namun di sisi lain, batimetri pada perairan dangkal $(<15 \mathrm{~m})$ sangat sulit dilakukan karena kesulitan dalam navigasi agar kapal tidak karam dan adanya terumbu karang di perairan dangkal sehingga dapat menyebabkan data menjadi tidak akurat (Eren et al., 2016; Webster et al., 2016; Wright et al., 2016), padahal
\end{abstract}

\footnotetext{
1) Pusat Pemetaan Kelautan dan Lingkungan Pantai, Badan Informasi Geospasial

2) Bidang Penelitian, Badan Informasi Geospasial
} 
informasi spasial di area pesisir ini sangat dibutuhkan. Oleh karena itu, teknologi penginderaan jauh dibutuhkan untuk membantu mendeteksi kedalaman di daerah tersebut.

Salah satu teknologi penginderaan jauh yang dapat digunakan untuk mendukung survei hidrografi ialah Bathymetric LIDAR (Light Detection and Ranging). Bathymetric LIDAR memberikan informasi spasial dasar untuk mendukung analisis lanjut seperti distribusi sumber daya kelautan, kelimpahan, hubungan biogeografis biota, mengevaluasi dampak sesaat dan jangka panjang dari tekanan alam dan antropogenik, mempertimbangkan kebijakan/regulasi

pengembangan kawasan pesisir, dan mendukung upaya resiliensi dan restorasi (Kim et al., 2017).

LIDAR mampu mendeteksi objek di darat dan perairan dikarenakan diterbangkan dengan wahana. Sapuan LIDAR yang lebar membuat perolehan data menjadi cepat dan efektif dibandingkan dengan pemeruman akustik. Perbandingan sapuan LIDAR dan pemeruman akustik dapat dilihat pada Gambar 1. Oleh karena itu, LIDAR menjadi salah satu alternatif untuk mendapatkan data kedalaman terutama di daerah pesisir dengan kedalaman kurang dari 50 m (Banic \& Cunningham, 1998).

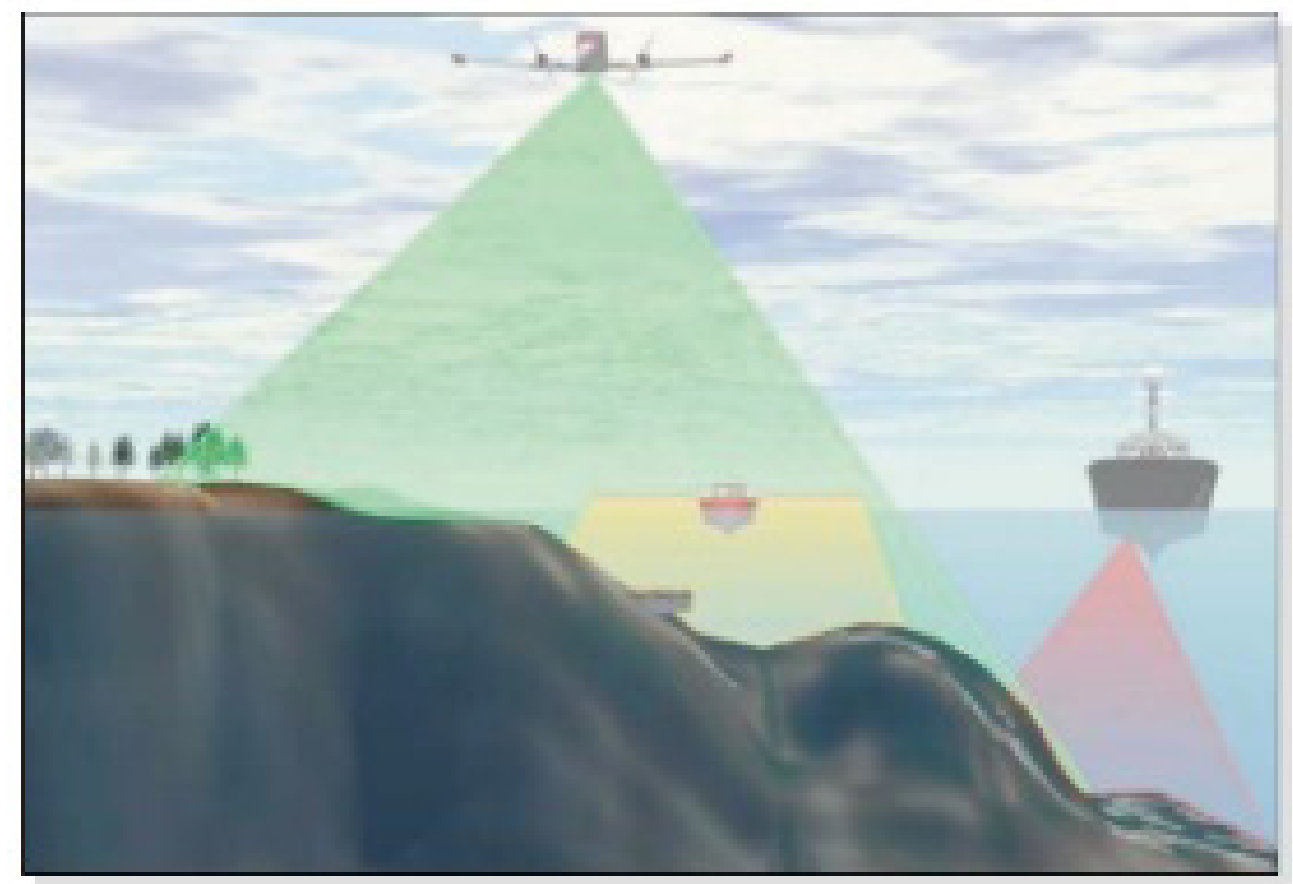

Gambar 1. Konsep LIDAR dibandingkan dengan pemeruman akustik (Banic \& Cunningham, 1998). 
PERKEMBANGAN BATHYMETRIC LIDAR

Lidar diperkenalkan pada pertengahan tahun 1960 dengan demonstrasi pertama pada tahun 1969 (Forfinski-Sarkozi \& Parrish, 2016). Secara khusus, Bathymetric LIDAR diperkenalkan pada tahun 1970-an di dalam program NASA yang bernama Airborne Oceanographic Lidar (AOL). AOL merupakan proyek eksperimental dan uji lapangnya membuktikan bahwa LIDAR sangat berpotensi untuk pemetaan dasar laut. AOL menggunakan laser dengan panjang gelombang $540 \mathrm{~nm}$ (Guenther et al., 1978).

Kanada juga mengembangkan Bathymetric LIDAR yaitu LARSEN 500 hasil kerja sama perusahaan OPTECH dengan Pusat Penginderaan Jauh Kanada (Canada Centre for Mapping and Earth Observation). LARSEN 500 menggunakan dua gelombang cahaya yaitu hijau $(532 \mathrm{~nm})$ dan inframerah (1.064 nm) untuk mendeteksi kedalaman (Banic et al., 1986).OPTECH mengembangkan versi pertama dengan sistem yang dinamakan SHOAL (Scanning Hydrographic Operational Airborne Lidar Survey).

Angkatan Laut Australia dan angkatan bersenjata Swedia kemudian mengikuti dengan membuat sistem yang mereka kembangkan sendiri yaitu Laser Airborne Depth Sounder (LADS) dan Hawk Eye mulai tahun 1989. Pada tahun
2000, kolaborasi antara U.S. Army Corp of Engineers, U.S. Geological Survey, U.S. National Ocean Service, dan Canadian Hydrographic Service, menunjukkan ketertarikan lebih lanjut pada teknologi Bathymetric LIDAR dengan membuat sistem yang lebih handal dan mudah digunakan (Saylam et al., 2017).

\section{PRINSIP KERJA BATHYMETRIC LIDAR}

Bathymetric LIDAR menggunakan laser untuk menduga kedalaman dasar perairan dari perbedaan waktu pengiriman pulsa sinar optik yang ditransmisikan dari wahana ke dasar perairan melewati medium udara dan air. Pulsa optik yang dihasilkan oleh laser ditransmisikan dari wahana menuju permukaan air. Penerima optik yang berada di sebelah transmiter mendeteksi pulsa yang kembali dari permukaan dan dasar air.

Secara umum, Bathymetric LIDAR menggunakan dua panjang gelombang cahaya yaitu hijau (532 $\mathrm{nm})$ dan inframerah (1064 nm) untuk mendeteksi permukaan dan dasar perairan (Gambar 2). Sinar hijau digunakan karena mampu menembus air hingga ke dasar. Adapun sinar inframerah digunakan sebagai faktor pengurang jarak yang dideteksi sinar hijau, karena sinar inframerah tidak bisa menembus permukaan air. 


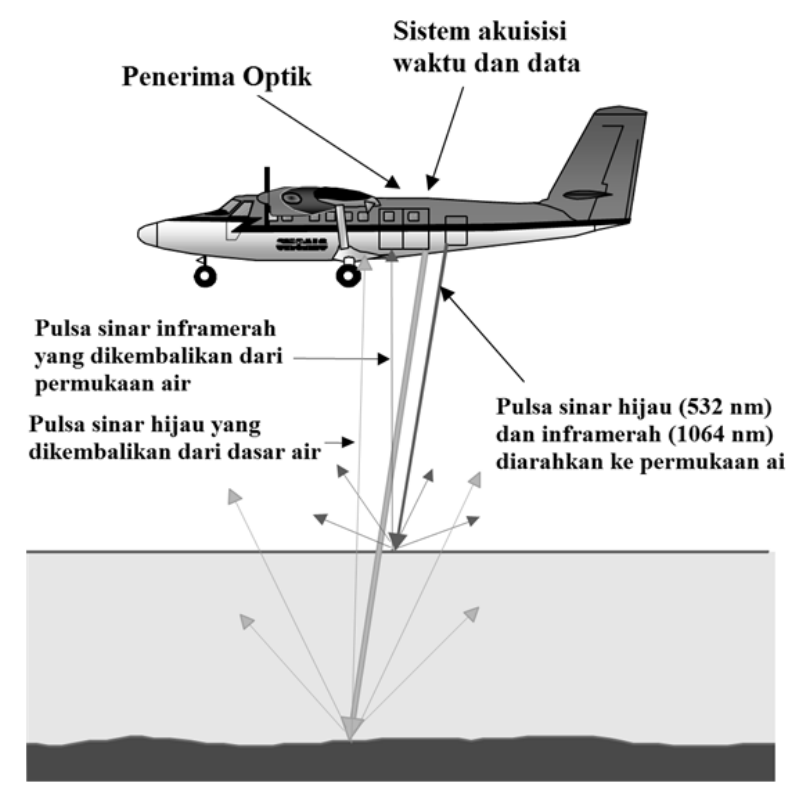

Gambar 2. Prinsip Operasi Bathymetric LIDAR (LaRocque \& West, 1999).

Bentuk gelombang Bathymetric LIDAR biasanya terdiri dari dua puncak signifikan yang merepresentasikan energi sinar laser yang direfleksikan dari permukaan air dan energi yang direfleksikan dari dasar perairan (Eren $e t$ al.,2016). Di dalamkolom perairan, energi sinar laser mengalami penghamburan dan penyerapan. Kedalaman perairan dihitung dari perbedaan waktu antara sinyal kembali dari dua laser ini (waktu kembali dari dasar dan permukaan air). Bentuk sinyalnya dapat dilihat pada Gambar 3. Sinyal akan kembali menjadi derau (noise) setelah berinteraksi dengan lingkungan (LaRocque \& West, 1999; Kim et al., 2017).

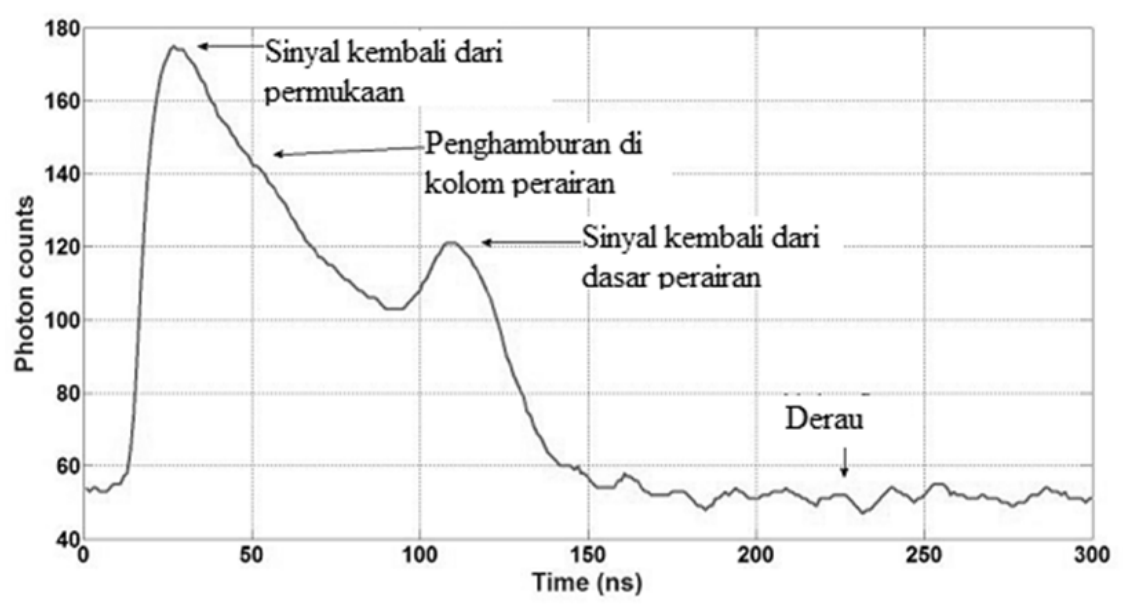

Gambar 3. Bentuk gelombang yang diterima oleh Bathymetric LIDAR (Eren et al., 2016). 


\section{INSTRUMEN LIDAR}

Instrumen Bathymetric LIDAR sudah berkembang saat ini. Beberapa di antaranya ialah:
1. OPTECH Scanning Hydrographic Operational Airborne Lidar Survey (SHOALS) System

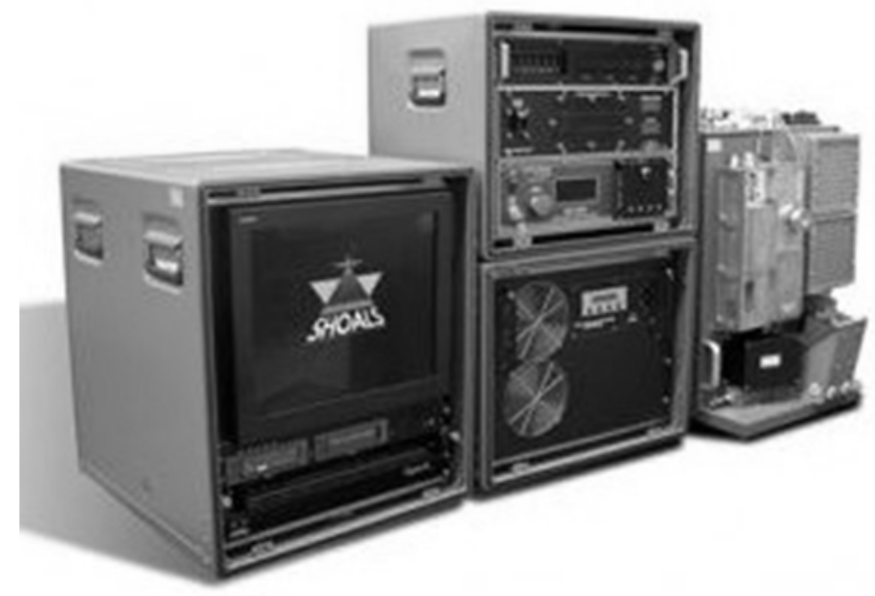

Gambar 4. Bentuk fisik OPTECH SHOALS (GIM International, 2008).

Instrumen ini dikembangkan oleh US Navy dan OPTECH untuk mengukur kedalaman perairan dangkal dan elevasi daratan tepi pantai. Sistem ini bekerja pada frekuensi $200 \mathrm{~Hz}$ dan $400 \mathrm{~Hz}$ dengan pengoperasian menggunakan helikopter. Ketinggian wahana optimumnya yaitu antara 200-400 m dengan kecepatan 50-70 $\mathrm{m} / \mathrm{s}$. Panjang gelombang yang digunakan ialah $532 \mathrm{~nm}$ dan $1064 \mathrm{~nm}$. Lebar sapuan sistem ini sepanjang $220 \mathrm{~m}$. Ketelitian pengukuran sistem ini mengikuti standar IHO Ordo 1 yaitu $\pm 0,15 \mathrm{~m}$ secara vertikal dan $\pm 1-3 \mathrm{~m}$ secara horisontal. SHOALS memiliki kemampuan untuk mendeteksi kedalaman 2 sampai 3 kali menggunakan Secchi Disk. Pada kondisi perairan yang jernih, SHOALS mampu mendeteksi hingga $60 \mathrm{~m}$ (Wozencraft \& Lillycrop, 2002).
2. Compact Hydrographic Airborne Rapid Total Survey (CHARTS) system

CHARTS system dikembangkan oleh US Navy dan OPTECH untuk memenuhi kebutuhan angkatan laut Amerika Serikat dalam pembuatan peta laut. CHARTS merupakan generasi penerus SHOALS (Gambar 5). Sistem ini memiliki kemampuan untuk mengaktifkan laser yang akan digunakan. Pengguna bisa memilih mengaktifkan sinar inframerah saja atau inframerah dan hijau sesuai dengan peruntukannya. Lebar sapuannya $70 \%$ dari ketinggian wahana. Akurasi vertikal dan horizontal memenuhi standar IHO Ordo 1. Kedalaman minimum yang mampu dideteksi sebesar $0,1 \mathrm{~m}$ dan kedalaman maksimum sebesar tiga kali kedalaman Secchi disk (Wozencraft \& Lillycrop, 2002). 


\section{CHARTS sensor suite}

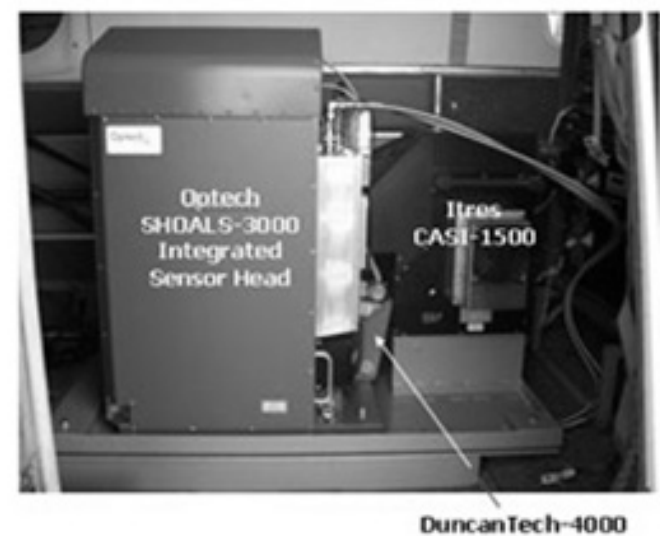

RGe Camera

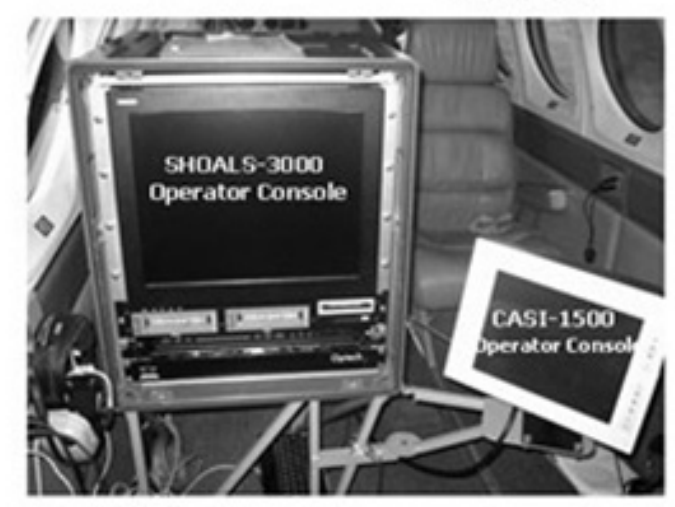

CHARTS operator station

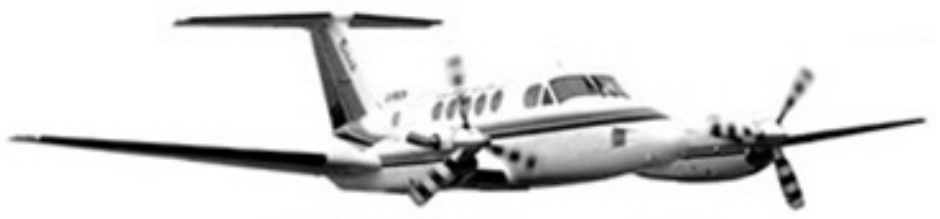

CHARTS airborne platform

Gambar 5. Instrumen yang ada pada CHARTS System (Joint Airborne Lidar Bathymetry Technical Center of Expertise \& U.S. Army Corps of Engineers) (Wozencraft \& Lillycrop, 2002)

3. Bathymetric and Topographic Survey

BATS system dikembangkan oleh (BATS) system US Navy dan OPTECH untuk operasi taktis. Sistem ini memenuhi standar IHO Ordo 2 (Gambar 6). 


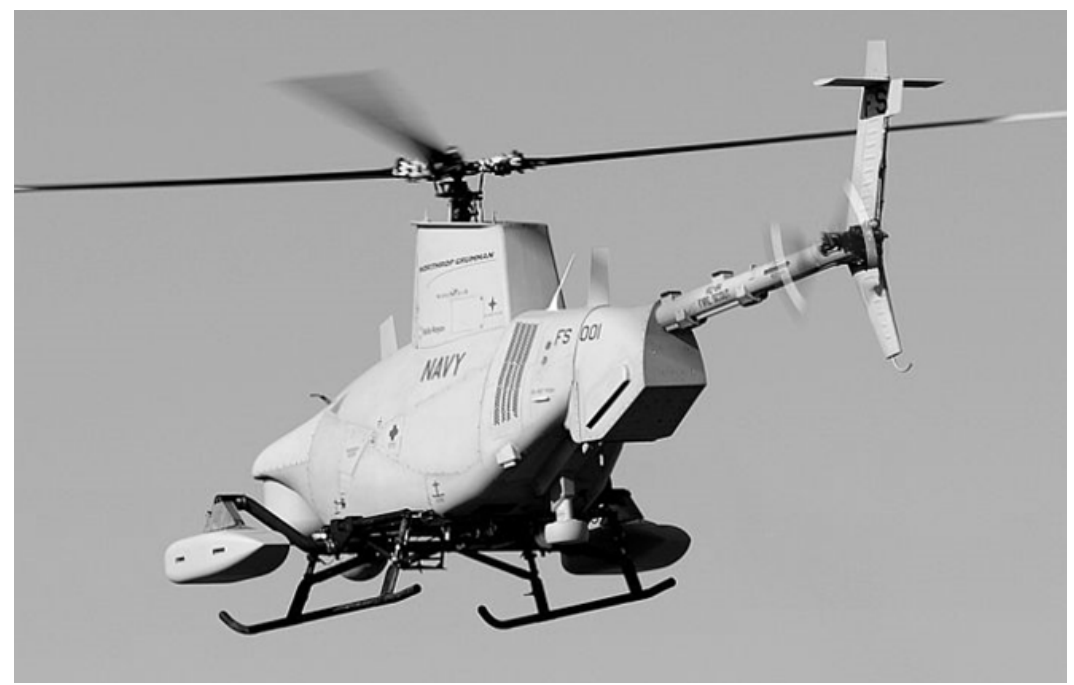

Gambar 6. Wahana tak berawak yang mengangkut BATS System (Wozencraft \& Lillycrop, 2002)

Lebar sapuannya $50 \%$ dari ketinggian wahana. Kedalaman minimum yang mampu dideteksi sebesar $1 \mathrm{~m}$ dan kedalaman maksimum sebesar 2,5 kali kedalaman Secchi disk (Wozencraft \& Lillycrop, 2002).

4. Coastal Zone Mapping and Imaging LIDAR (CZMIL) Nova

Sistem CZMIL dibuat oleh OPTECH dan digunakan untuk memenuhi permintaan Joint Airborne Lidar Bathymetry Technical Center of Expertise (JALBTCX) dalam kegiatan USACE National Coastal Mapping Program (Gambar 7).

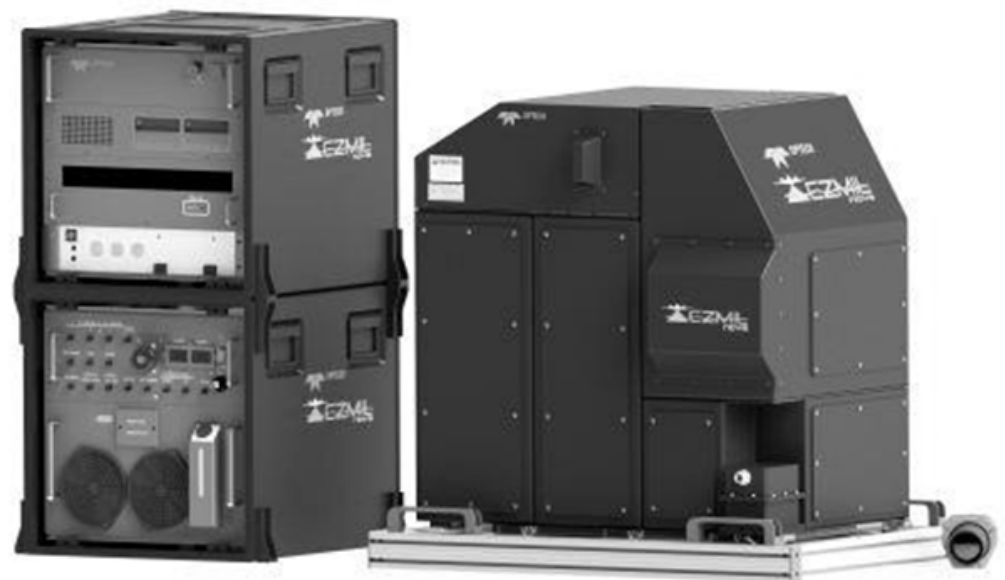

Gambar 7. Bentuk fisik Coastal Zone Mapping and Imaging Lidar (CZMIL) Nova (www.teledyneoptech.com). 
Sisteminibekerjapadaketinggian $400 \mathrm{~m}$ dengan kecepatan wahana 140 knot. Kedalaman maksimum yang dapat dideteksi sebesar 4 kali kedalaman Secchi disk. Akurasi horizontal sebesar 3,5 \pm $(0,05 \times$ kedalaman $) \mathrm{m}$, dan kedalaman vertikalnya sebesar Ö $(0,32 \pm(0,013 \mathrm{x}$ kedalaman $)^{2}$ ) m (Ramnath et al., 2015).

5. Leica Hawk Eye III

Hawk Eye III mampu mensurvei darat dan dasar perairan secara simultan menggunakan laser inframerah (1064 $\mathrm{nm})$ dan laser hijau (532 nm).

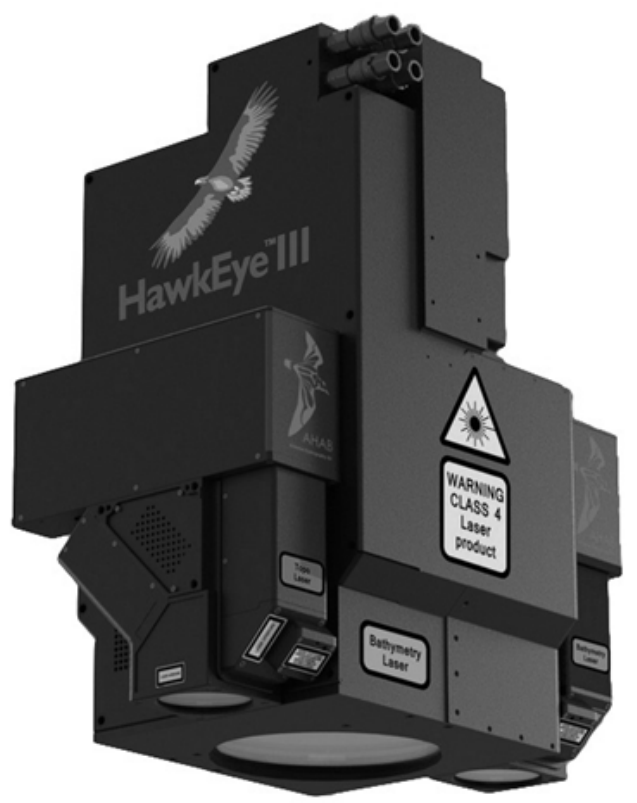

Gambar 8. Instrumen Bathymetric Laser HAWKEYE III (www.teledyneoptech.com).

Alat ini diterbangkan oleh wahana dengan ketinggian terbang antara $250 \mathrm{~m}$ hingga $600 \mathrm{~m}$. Sensor ini memiliki lebar sapuan sepanjang $100 \mathrm{~m}$ - $330 \mathrm{~m}$. Hawk Eye III mampu mengukur kedalaman dengan kerapatan 0,1 dan 0,35 pemeruman per $\mathrm{m}^{2}$ (Tulldahl, 2014).

\section{Leica Chiroptera-II}

Instrumen ini dikembangkan oleh Leica AHAB dan memiliki banyak penambahan dari Chiroptera I. Instrumen ini memiliki laser inframerah (1064 $\mathrm{nm})$ dan laser hijau $(515 \mathrm{~nm})$. Laser inframerah mengirim pulsa dengan frekuensi $500 \mathrm{kHz}$ sedangkan laser hijau sebesar $35 \mathrm{kHz}$. Kerapatan titik pengukuran batimetri pada ketinggian jelajah $400 \mathrm{~m}$ dengan kecepatan pesawat $60 \mathrm{~m} / \mathrm{s}$ ialah $1,5 \mathrm{titik} / \mathrm{m}^{2}$. Instrumen ini dilengkapi dengan Kamera Leica RCD30 untuk mendapatkan citra resolusi tinggi, dengan keakuratan batimetri sebesar 0,15 m. Leica Chiroptera II (Gambar 9) mampu mendeteksi kedalaman hingga 1,5 kali kedalaman Secchi disk (Webster, 2016). 


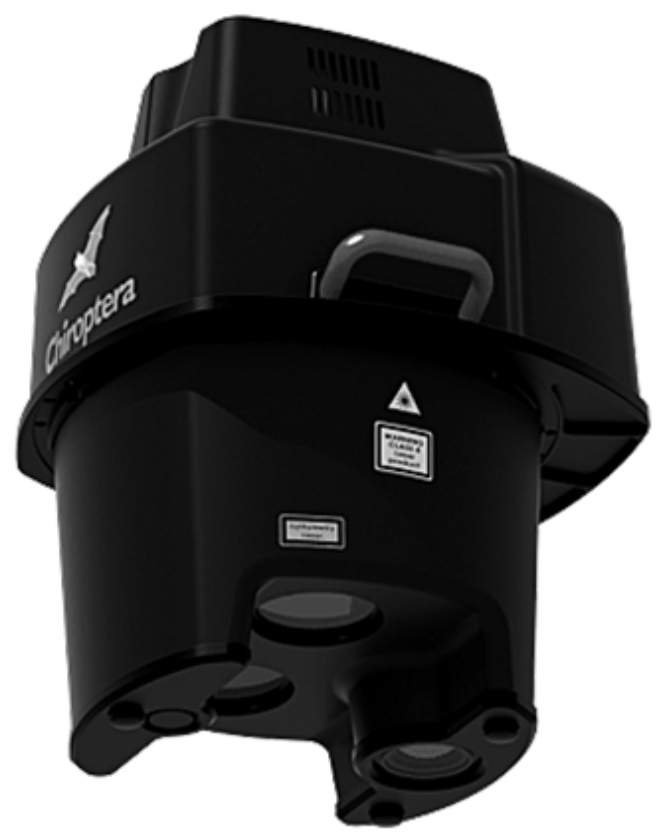

Gambar 9. Leica Chiroptera II (www.teledyneoptech.com).

\section{KEUNGGULAN DAN KEKURANGAN BATHYMETRIC LIDAR}

Keunggulan dari Bathymetric LIDAR antara lain adalah: (a) akurat dan kemampuan pendeteksian objek, LIDAR mampu memberikan akurasi sesuai dengan standar IHO (International Hydrographic Organization) ordo 1; (b) biaya yang dibutuhkan untuk pengoperasian Bathymetric LIDAR lebih murah dibandingkan dengan Multibeam echosounder (MBES). Rasio biaya antara LIDAR dan MBES ialah 3:10 untuk deteksi kedalaman kurang dari $50 \mathrm{~m}$; (c) area cakupan LIDAR lebih luas dibandingkan dengan MBES. LIDAR mampu memindai area hingga $77 \mathrm{~km}^{2} / \mathrm{jam}$. Hal ini dikarenakan lebar sapuan LIDAR tidak dipengaruhi oleh kedalaman; (d) kemampuan operasi di daerah yang berbahaya dan tidak bisa dilalui oleh survei MBES; (e) tingkat fleksibilitas yang tinggi membuat LIDAR mampu memberikan data yang akurat dan cepat; (f) mampu mendeteksi ketinggian darat dan kedalaman pada waktu yang bersamaan; dan (g) mampu memberikan informasi intensitas yang kembali dari objek untuk digunakan dalam pengelompokan bentik (LaRocque \& West, 1999; Brock \& Purkis, 2009; Gupta \& Zielinski, 2013).

Kekurangan dari Bathymetric LIDAR ini ialah: (a) kemampuan pendeteksian kedalaman dipengaruhi oleh kekeruhan perairan dimana semakin keruh perairan semakin dangkal kedalaman yang bisa dideteksi. Bathymetric LIDAR hanya mampu mendeteksi kedalaman kurang dari $50 \mathrm{~m}$ pada perairan yang jernih dan sekitar 20- 
30 m pada perairan tidak terlalu keruh; (b) gelombang yang disebabkan angin memengaruhi produktivitas LIDAR sehingga target yang kecil tidak mampu dideteksi; (c) kondisi lingkungan seperti hujan, angin yang kencang, gelombang yang tinggi, kabut, lereng yang curam menyebabkan kesulitan pada survei LIDAR (Guenther et al., 1978; Sizgoric et al., 1995; Gupta \& Zielinki, 2013).

\section{APLIKASI DENGAN MENGGUNAKAN BATHYMETRIC LIDAR}

Bathymetric LIDAR sudah digunakan di beberapa negara sebagai salah satu solusi untuk mendapatkan data di kawasan pesisir secara cepat, aman, dan berkualitas. Data yang diambil di kawasan pesisir dengan LIDAR tidak hanya data batimetri melainkan datadata lain seperti garis pantai, tutupan lamun, deteksi situs purbakala di dalam air, deteksi tipe substrat dasar perairan dangkal, hingga studi mengenai ekosistem terumbu karang (Guenther et al., 1978, Brock \& Purkis, 2009; Doneus et al., 2012).
Secara spesifik, Bathymetric LIDAR memberikan nilai kedalaman yang presisi. Banic \& Cunningham (1998) menjelaskan kemampuan SHOALS system dalam pembuatan peta tiga dimensi Teluk Braviken, Swedia (Gambar 10). Gambar 11 menunjukkan kemampuan Bathymetric LIDAR dalam memberikan informasi tentang keberadaan kapal karam di perairan Meksiko dari hasil interpretasi data Bathymetric LIDAR (LaRocque \& West, 1999). Selain itu, U.S Geological Survey (USGS) memperoleh data batimetri di pesisir Hawai menggunakan Bathymetric LIDAR (Gambar 12). Data batimetri dan topografi ini digunakan untuk pembuatan Seamless Digital Terrain Model yang dapat digunakan untuk manajemen kawasan pesisir dan desain teknik. Ramnath et al., (2015) melakukan survei hidrografi di Hawai dengan menggunakan CZMIL untuk menyempurnakan data yang diperoleh USGS. Hasil pemindaian CZMIL dianalisis menjadi Seamless Digital Terrain Model (Gambar 13). Begitu pula dengan Quadros et al., (2008) yang mampu memindai Teluk Port Phillip, Victoria, Australia dan menggabungkannya dengan topographic LIDAR (Gambar 14). 


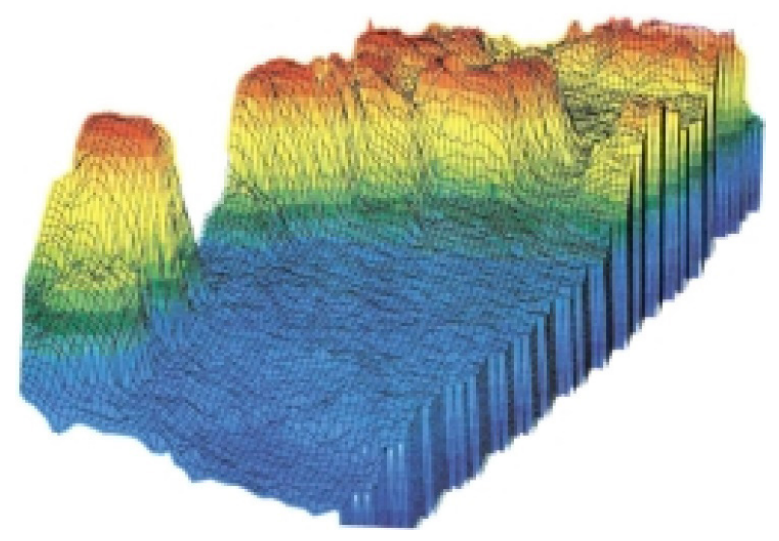

Gambar 10. Peta tiga dimensi Teluk Braviken Swedia yang diambil menggunakan Bathymetric LIDAR (Banic \& Cunningham, 1998).
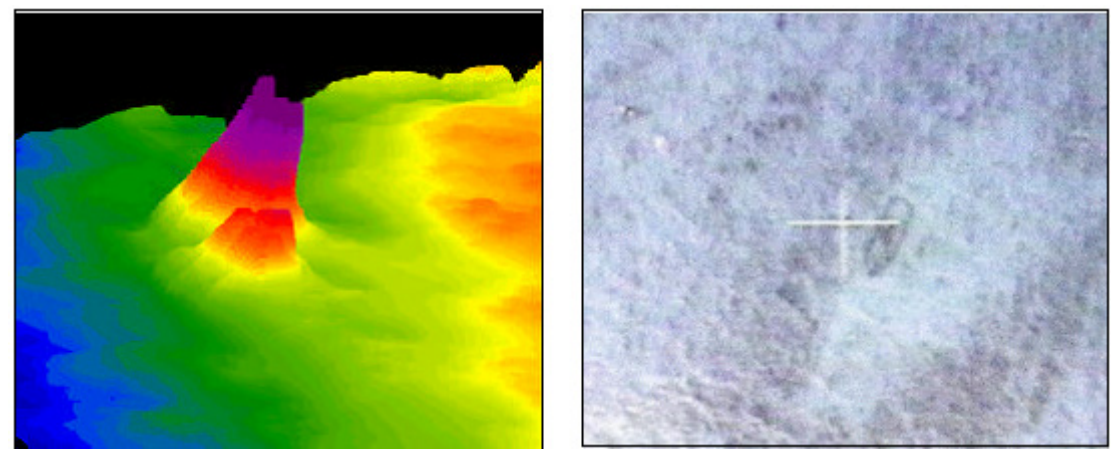

Gambar 11. Bagian kapal karam yang teridentifikasi oleh Bathymetric LIDAR (kiri); keberadaan kapal karam di dasar perairan dengan menggunakan citra (kanan). (LaRocque \& West, 1999).

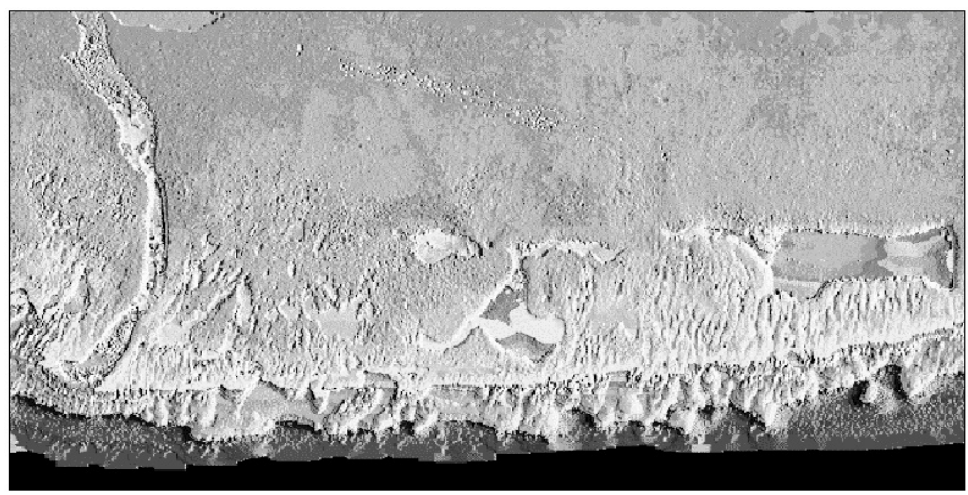

Gambar 12. Citra dari data Bathymetric LIDAR di Hawai. Garis pantai berada di atas, lepas pantai di bawah, dan warna keabuan mengindikasikan kedalaman dengan warna yang semakin gelap menunjukkkan perairan yang semakin dalam (Irish, 2000). 


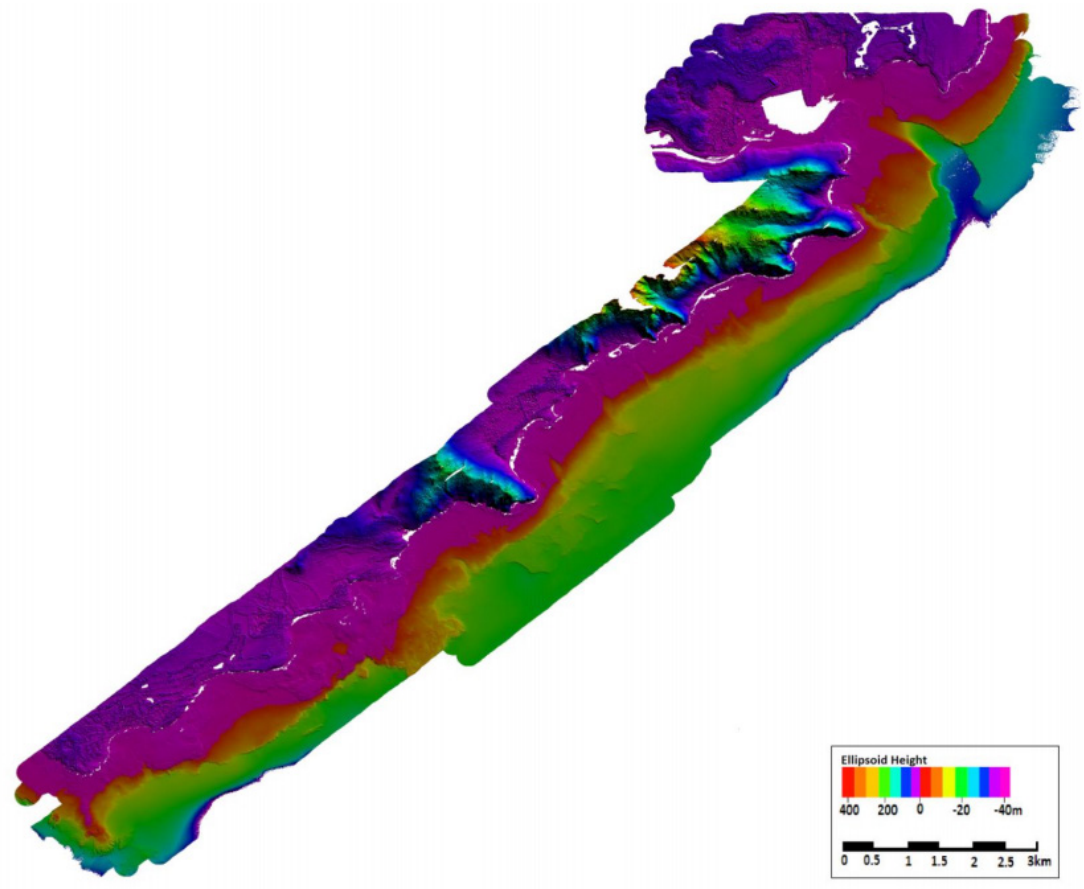

Gambar 13. Peta Topo-bathy DEM yang dibentuk dari data CZMIL di Hawai (Ramnath et al., 2015).

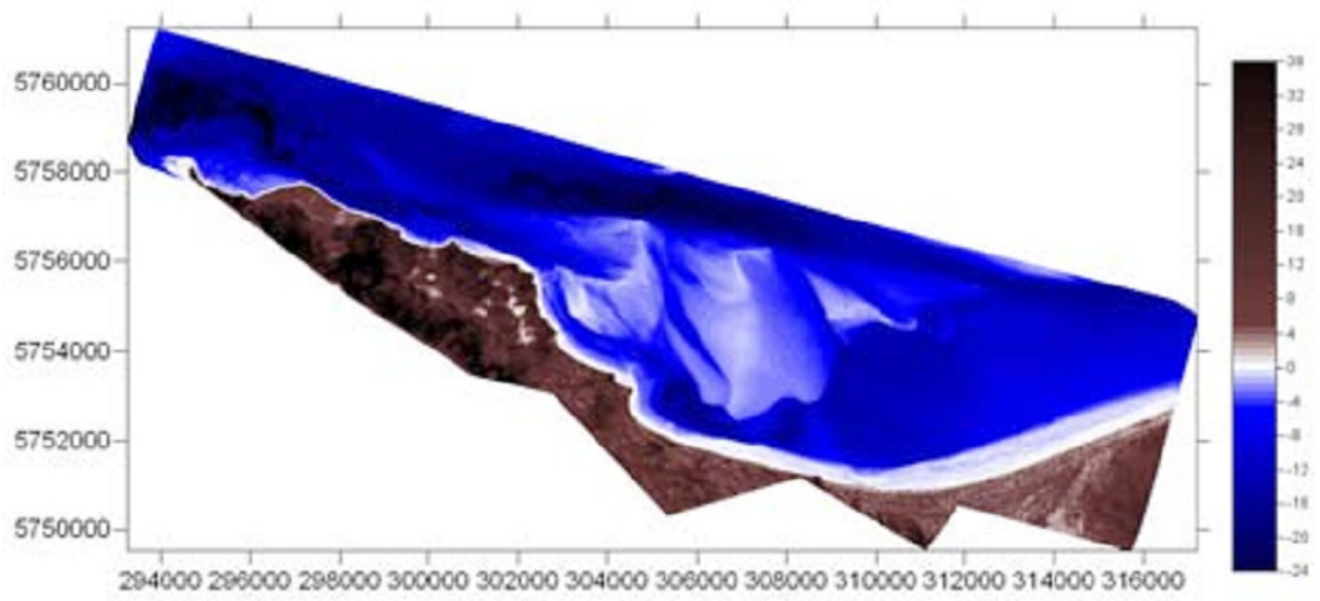

Gambar 14. Hasil pemindaian Bathymetric LIDAR di Teluk Port Phillip, Victoria, Australia (Quadros et al., 2008) 
Pastol (2011) mencoba membandingkan tiga instrumen yaitu Bathymetri LIDAR, Topographic LIDAR, dan Multibeam Echosounder dalam pembuatan peta batimetri di daerah pesisir
Perancis (Gambar 15). Wilson (2011) memperlihatkan bentuk tiga dimensi ekosistem terumbu karang di Laut Merah dari hasil pemindaian Bathymetric LIDAR (Gambar 16.).
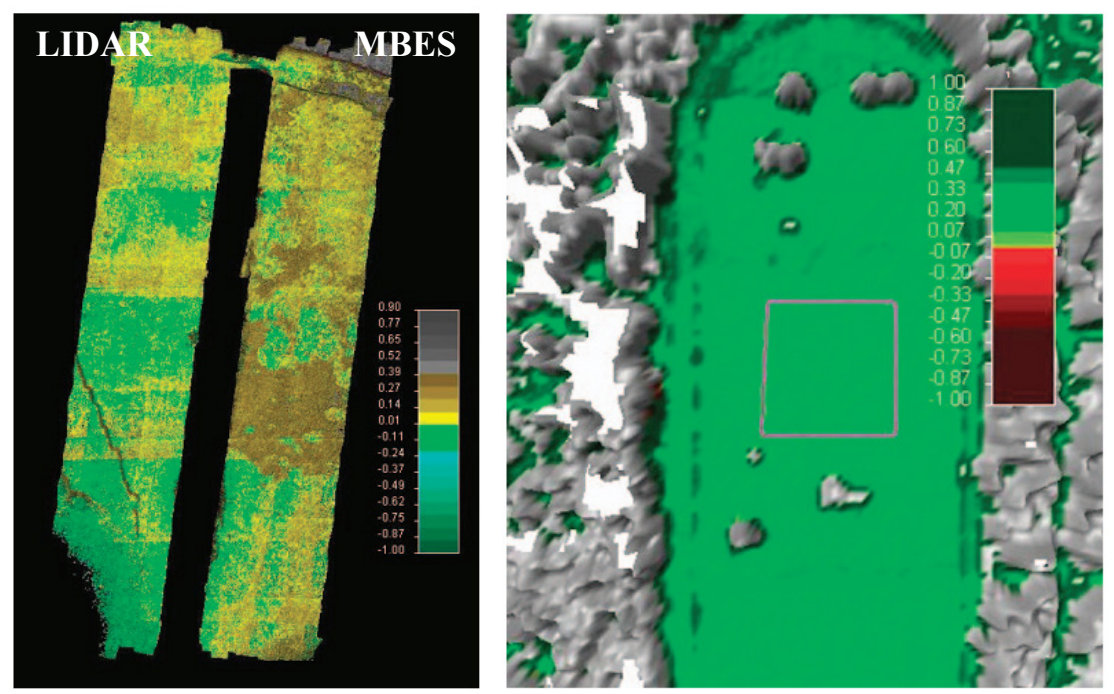

Gambar 15. Perbedaan hasil nilai kedalaman dari LIDAR dan MBES (kiri); Perbedaan nilai ketinggian yang dihasilkan oleh Topographic LIDAR dan Bathymetric LIDAR dalam satuan meter (Pastol, 2011).

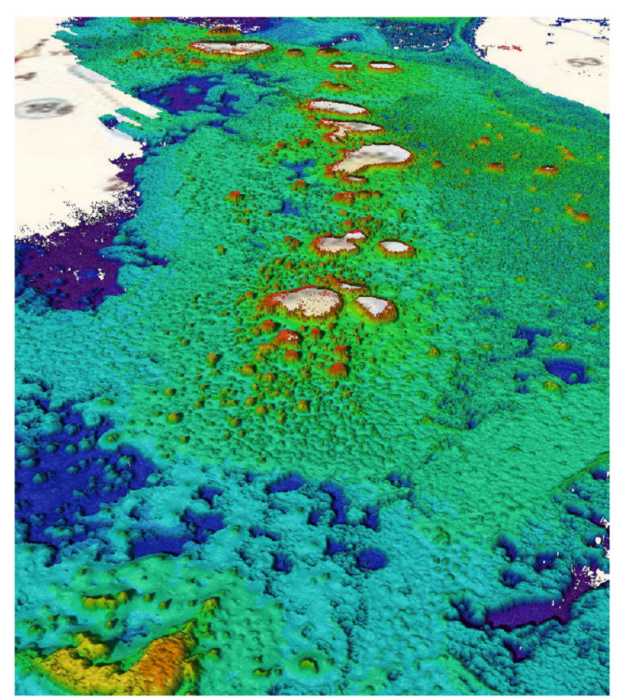

Gambar 16. Area terumbu karang yang disurvei dengan Bathymetric LIDAR di Laut Merah (Wilson, 2011). 


\section{PENUTUP}

Bathymetric LIDAR sebagai salah satu teknologi penginderaan jauh yang sudah berkembang saat ini mampu menjadi solusi alternatif untuk memperoleh data batimetri di kawasan pesisir dengan kedalaman kurang dari 50 meter. Penggunaan Bathymetric LIDAR akan membantu untuk memperoleh data di kawasan pesisir Indonesia dan dapat digunakan untuk kepentingan pembuatan peta lingkungan pantai, peta alur pelayaran, hingga peta tematik lainnya. Namun, adanya kekurangan Bathymetric LIDAR yaitu kualitas data dipengaruhi oleh kekeruhan perairan, maka penggunaan Bathymetric LIDAR tersebut perlu memperhatikan kondisi daerah yang akan disurvei.

Dengan adanya teknologi Bathymetric LIDAR ini diharapkan mampu mempercepat perolehan data batimetri yang selama ini hanya diperoleh dari data pemeruman akustik baik Singlebeam Echosounder maupun Multibeam Echosounder. Belum banyaknya aplikasi Bathymetric LIDAR di Indonesia menjadi peluang bagi peneliti, mahasiswa, dosen hingga praktisi untuk menggunakan dan mengembangkan Bathymetric LIDAR ini agar semakin banyak orang yang dapat menggunakannya.

\section{DAFTAR PUSTAKA}

Banic, J., S. Sizgoric, and R. O'Neil. 1986. Scanning lidar bathymeter for water depth measurement. In 1986 Quebec Symposium, 187195.

Banic, J. R., and A. G. Cunningham. 1998. Airborne laser bathymetry: A tool for the next millennium. EEZ Technology, 3 : 75-80.

Brock, J.C., and S. J. Purkis. 2009. The Emerging Role of Lidar Remote Sensing in Coastal Research and Resource Management Journal of Coastal Research, Special Issue, 53, 1-5. doi : 10.2112/SI53-001.1.

Chu, D. 2011. Technology evolution andadvances in fisheries acoustics. Journal of marine Science and Technology, 19(3) :245-252

Cunnigham, A. G., W. J. Lillycrop, G. C. Guenther and M. W. Brooks. 2016. Shallow water laser bathymetry accomplishments and applications. US Army Corps of Engineers Mobile United States.

Doneus M., N. Doneus, C. Briese, M. Pregesbauer, G. Mandlburger, and G. Verhouven. 2013. Airbone laser bathymetrydetecting and recording submerged archaeological sites from the air. Journal of Archaeological Science, 40(4) : 2136-2151. doi : 10.1016/j. jas.2012.12.021. 
Eren, F., S. Pe'eri, and Y. Rzhanov. 2016. Airborne Lidar Bathymetry (ALB) waveform analysis for bottom return characteristics. Proc. SPIE 9827, Ocean Sensing and Monitoring VIII, $\quad 98270 \mathrm{H}-98270 \mathrm{H}$. doi:10.1117/12.2224

Forfinski-Sarkozi, N.A., and C. E. Parrish, 2016. Analysis of MABEL Bathymetry in Keweenaw Bay and Implications for ICESat-2 ATLAS. Remote Sensing, 8(9) : 772 .

GIM International. 2008. Optech SHOALS [online]. http://giminternational.com/content/ news/optech-shoals.html. Diakses pada tanggal 28 Juli 2017.

Guenther G., L. Goodman, D. Enabnit, R. Swift and R. Thomas. 1978. Laser Bathymetry for Near Shore Charting Application (Preliminary Field Text Results). In OCEANS '78. Washington DC, USA, 390-396. doi : 10.1109/OCEANS . 1978.1151121

Gupta, S. D., and A. Zielinski. 2013. Acoustic and laser bathymetry systems. Hydroacoustics, 16 : 77-88. Retrieved from yadda. icm.edu.pl/yadda/ element/ bwmeta1.element.baztech9 cef 4 f 8 e- $5330-4 b f f-8 c 8 b-$ $656 f 9 a 4 f 57 \mathrm{eb} / \mathrm{c} /$ Gupta.pdf.
Irish, J.L. 2000. An introduction to coastal zone mapping with airborne lidar: The Shoals System. Diunduh dari https:// apps.dtic.mil/dtic/tr/fulltext/u2/ a492313.pdf

Kim, H. S. B. Lee, and K. S. Min. 2017. Shoreline change analysis using airborne LiDAR bathymetry for coastal monitoring. In: Lee, J.L.; Griffiths, T.; Lotan, A. K. S. Suh, and J. Lee. (eds.), The 2nd International Water Safety Symposium. Journal of Coastal Research, Special Issue, 79: 269-273.

LaRocque, P. E., and G. R. West. 1999. Airborne laser hydrography: an introduction. In Proc. ROPME/ PERSGA/IHB Workshop on Hydrographic Activities in the ROPME sea area and Red Sea, $4: 1-15$

Pastol, Y. 2011). Use of airborne LIDAR bathymetry for coastal hydrographic surveying: the French experience. Journal of Coastal Research, 6-18.

Quadros, N. D., P. A. Collier, and C. S. Fraser. 2008. Integration of Bathymetric and topographic LiDAR: a preliminary investigation. The International Archivesof the Photogrammetry, Remote Sensing and Spatial Information Sciences, 36: 1299-1304. 
Ramnath, V., V. Feygels, H. Kalluri, and B. Smith. 2015. CZMIL (Coastal Zone Mapping and Imaging Lidar) Bathymetric performance in diverse littoral zones. In OCEANS'15 MTS/ IEEE Washington, 1-10.

Saylam, K., R. A. Brown, and J. R. Hupp. 2017. Assessment of depth and turbidity with airborne Lidar bathymetry and multiband satellite imagery in shallow water bodies of the Alaskan North Slope. International Journal of Applied Earth Observation and Geoinformation, 58: 191-200.

Sizgoric, S., J. Banic, and P. LaRocque. 1995. The History of Laser Bathymetry. In G. A. Lampropoulos, J. Chrostowski, \& R. M. Measures (Eds.), Applications of Photonic Technology (pp. 207-217). Boston, MA: Springer US. doi: 10.1007/978-1-4757-9247$8 \_40$

Tulldahl, H. M. 2014. Processing of airborne lidar bathymetry data for detailed sea floor mapping. In Proc. SPIE 9250, ElectroOptical Remote Sensing, Photonic Technologies, and Applications VIII; and Military Applications in Hyperspectral Imaging and High Spatial Resolution Sensing II, 92500E. doi:10.1117/12.2068940
Webster, T., K. McGuigan, N. Crowell, K. Collins, and C. MacDonald. 2016. Optimization of data collection and refinement of post-processing techniques for Maritime Canada's first shallow water topographicBathymetric lidar survey. In: Brock, J.C., Gesch, D.B., Parrish, C.E., Rogers, J.N., \& Wright, C.W. (eds.), Advances in TopoBathymetric Mapping, Models, and Applications. Journal of Coastal Research, Special Issue, 76: 31-43. doi: $10.1117 / 12.2224335$

Wilson, J. C. 2011. Mapping coral reef complexes using airborne LiDAR bathymetry technology. In OCEANS 2011 (1-5).

Wozencraft, J. M., and W. J. Lillycrop. 2002. Total shallow-water survey through airborne hydrography. Corps of Engineers Mobile Al Mobile District

Wright, C. W., C. Kranenburg, T. A. Battista, and C. Parrish. 2016. Depth Calibration and Validation of the Experimental Advanced Airborne Research Lidar, EAARL-B. Journal of Coastal Research, 76 (sp1), 4-17. 